\title{
Analysis on fluorescence, structure, functional group and optical behaviour of iso-leucine and zinc acetate doped iso-leucine crystals
}

\author{
M.V.T. Sumathe ${ }^{1}$ V.S. Kumar ${ }^{2 *}$ R.S. Sundararajan ${ }^{3}$ \\ ${ }^{1,3}$ Department of Physics, Government Arts College(Autonomous), Kumbakonam, India \\ ${ }^{2}$ Department of Physics, Swami Dayananda College of Arts and Science, Manjakkudi, India \\ *Corresponding author e-mail: shanmugavsk.2010@gmail.com
}

Available online at: www.isroset.org

Accepted: 15/Aug/2018, Online: 31/Aug/2018

\begin{abstract}
Single crystals of isoleucine and zinc acetate doped iso leucine crystals have been grown by slow evaporation technique. Good quality crystals were grown in 90 days. The fluorescence of the crystals were analyzed by fluorescence studies. FTIR spectrum reveals the presence of functional groups of the crystal. SEM analysis divulges the structural morphology of LISOL and LISZA crystals. The crystals have good optical nature in the entire UV-Visible region.
\end{abstract}

Keywords- LISOL - L- Isoleucine ; LISZA - L-Isoleucine zinc acetate; FTIR - Fourier transform infrared spectrum; UV-VIS region - Ultra Violet-visible region, SEM- Scanning Electron Microscope.

\section{INTRODUCTION}

A material which satisfies optical transparency and stability is suitable for the opto-electronics device production. It is very difficult to identify such a material with all requirements. Number of amino acid complexes with inorganic compound play a vital role in second harmonic generation applications. Amino acid having a centric crystallographic structure with the absence of strong conjugated bonds leads to wide transparency in the entire UV-Visible region[1].

In this paper, we report the growth and characterization of a material that is isoleucine and Zinc acetate mixed isoleucine (LISZA). The grown crystal is effective in giving good optical behavior which can be utilized for optoelectronic device fabrications.

\section{EXPERIMENTAL PROCEDURE SYNTHESIS}

High purity salts(99.9\%) were used for the crystal growth. Single crystals of iso-leucine and zinc acetate doped iso-leucine were grown at room temperature by solution growth using slow evaporation method, of an aqueous solution containing pure iso leucine and zinc acetate with isoleucine in equal stoichiometric ratio. The temperature of water in the bath was controlled digitally by using microprocessor. Variation in temperature of the bath can be tuned to an accuracy of $\pm 0.1^{\circ} \mathrm{C}$. Transparent good quality crystals of the title compound were harvested in span of 90 days. The photograph of the LISOL and LISZA crystals are shown in fig.1.

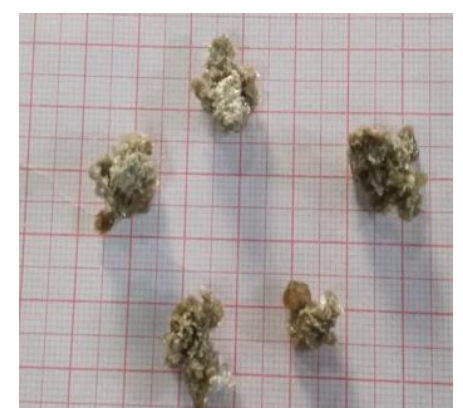

Fig.1(a) Photograph of LISOL

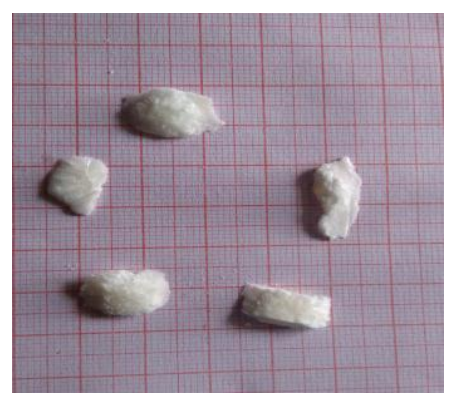

Fig.1(b) Photograph of LISZA

\section{CHARACTERIZATION}

The fluorescence studies of the grown LISOL and LISZA crystals were carried out using LS45 fluorescence spectrometer.. FTIR spectrum analysis was recorded in the range of $4000-400 \mathrm{~cm}^{-1}$ using Perkin Elmer spectrum RX I. 
The UV-Visible spectrum was recorded in the range 200nm1100nm using Perkin Elmer lambda 35 model. Surface morphology of the crystal was visualized by Scanning Electron Microscope.

\section{RESULTS AND DISCUSSION}

\section{a. Fluorescence studies}

LS45 Fluorescence spectrometer was used to record the fluorescence spectrum of the crystal. The fluorescence spectra of the pure isoleucine crystal was shown in the figure. The fluorescence crystal was recorded in the range 240 to $700 \mathrm{~nm}$, The excitation wavelength for grown up LISOL crystal was found to be $246 \mathrm{~nm}$. The sharp peak was observed at $453.90 \mathrm{~nm}$ in the emission spectrum of LISOL. The emission peak confirms that the crystal have blue fluorescence emission spectrum. LISZA crystal samples were also recorded in the range 240 to $700 \mathrm{~nm}$. The excitation wavelength for grown up LISZA crystals was found to be $245.53 \mathrm{~nm}$. The sharp peak was observed at $454.35 \mathrm{~nm}$ in the emission spectrum of LISZA.

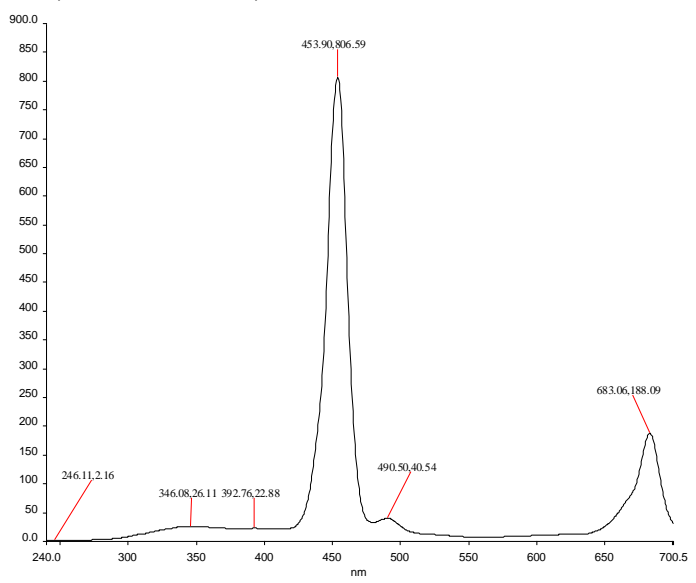

Fig.2(a) Fluorescence peak of L-isoleucine

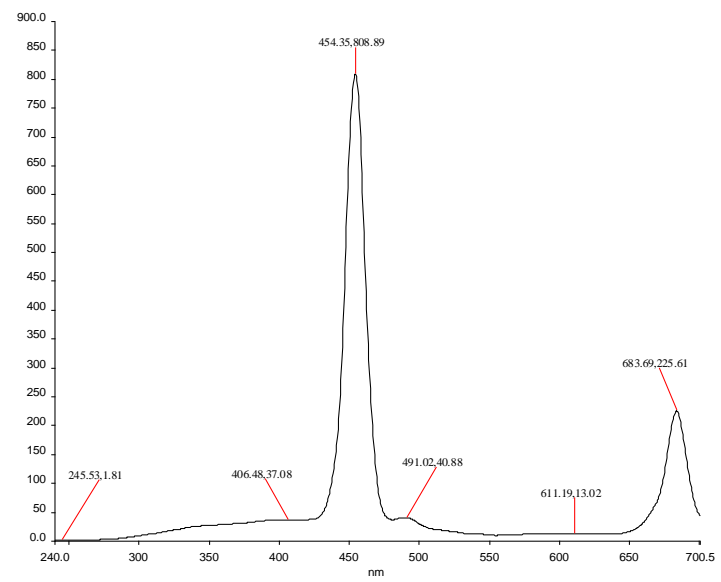

Fig.2(b) Fluorescence peak of zinc acetate mixed with Lisoleucine

\section{b. $\quad$ Fourier Transform Infrared spectrum studies}

The FTIR spectrum was recorded for the sample of the crystals using the $\mathrm{KBr}$ pellet technique in the region 4000$400 \mathrm{~cm}^{-1}$

The various functional groups present in the material are identified in this study[2-5]. The FTIR spectrum is shown in fig. 3 .

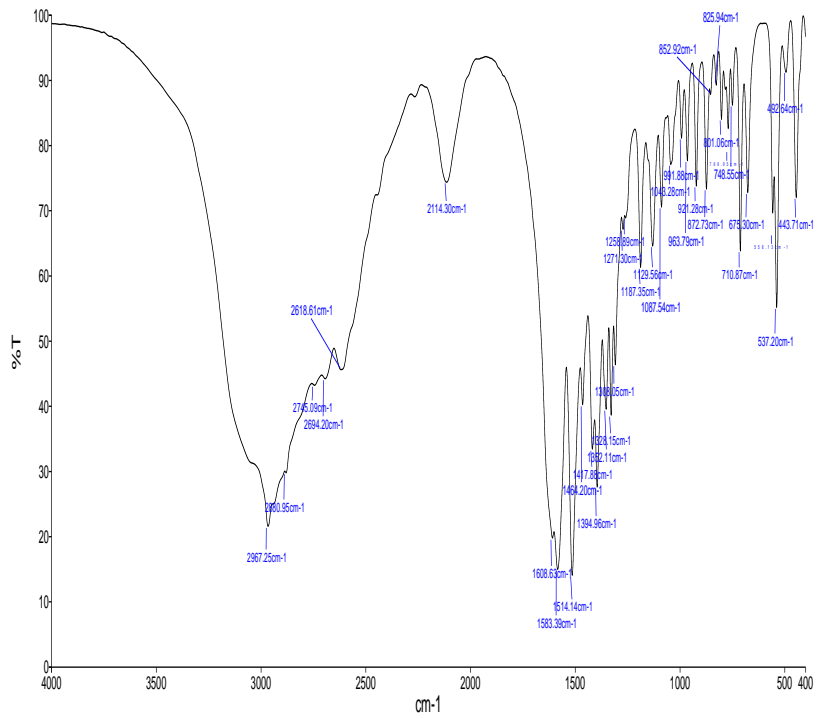

Fig.3(a) FTIR of LISOL

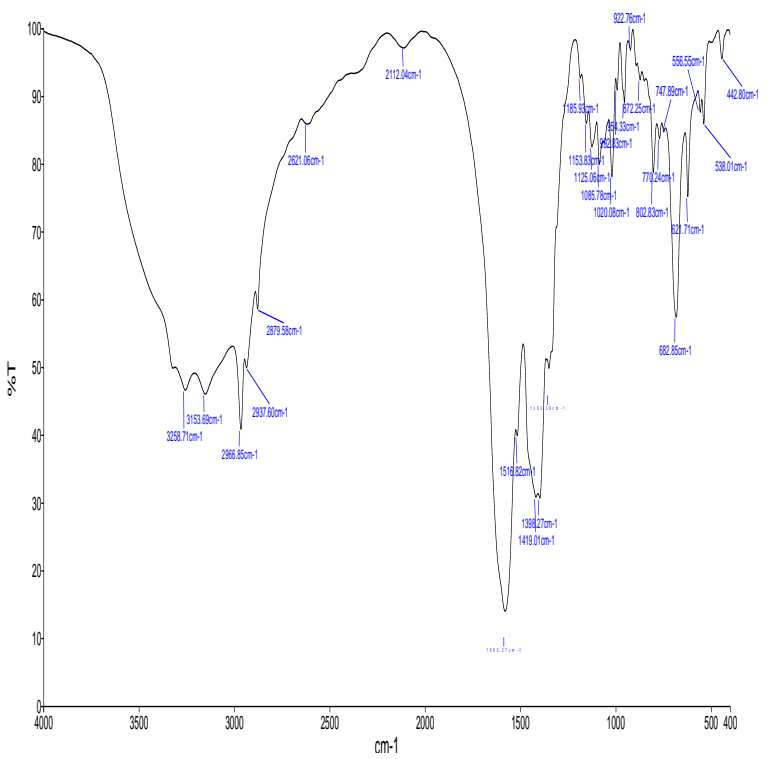

Fig.3(b) FTIR of LISZA

Table: Assignment modes from FTIR spectrum

\begin{tabular}{|c|c|l|}
\hline L-Isoleucine & LISZA & Assignment mode \\
\hline- & 3258 & $\mathrm{~N}-\mathrm{H}$ aminoacid stretching \\
\hline- & 3153 & $\mathrm{NH}_{3+}$ Asymmetric stretching \\
\hline 2967 & 2966 & $\mathrm{C}-\mathrm{H}$ stretching vibration \\
\hline- & 2937 & $\mathrm{C}-\mathrm{H}$ stretching vibration \\
& & \\
\hline
\end{tabular}




\begin{tabular}{|c|c|c|}
\hline 2880 & 2879 & $\begin{array}{l}\text { Presence of free amino acid with C- } \\
\mathrm{H} \text { stretching }\end{array}$ \\
\hline 2618 & 2621 & $\begin{array}{l}\text { Presence of aminoacid(weak); but } \\
\text { not always }\end{array}$ \\
\hline 2114 & 2112 & $\mathrm{C}-\mathrm{C}$ (triple bond) stretching \\
\hline 1417 & 1419 & $\mathrm{CH}_{3}$ symmetric bending \\
\hline- & 1153 & C-C Rocking \\
\hline 921 & 922 & $-\mathrm{O} \mathrm{C}\left(\mathrm{CH}_{3}\right)$ skeletal vibration \\
\hline 537 & 538 & $\mathrm{NO}_{2}$ deformation \\
\hline 442 & - & $\mathrm{C}-\mathrm{N}-\mathrm{C}$ bending \\
\hline
\end{tabular}

\section{c. $\quad U V$-Visible spectral studies}

The optical absorption spectra of LISOL and LISZA crystals were recorded in the region $200-1100 \mathrm{~nm}$ at a scanning speed of $480 \mathrm{~nm} / \mathrm{min}$. Fig. 4(a\&b) shows the absorbance spectra and transmission spectra which holds good in the entire visible region. The cutoff wavelength of LISOL was found to be $230 \mathrm{~nm}$ and $243 \mathrm{~nm}$ for LISZA. The optical behavior of this LISZA crystal was suitable for opto-electronic applications.

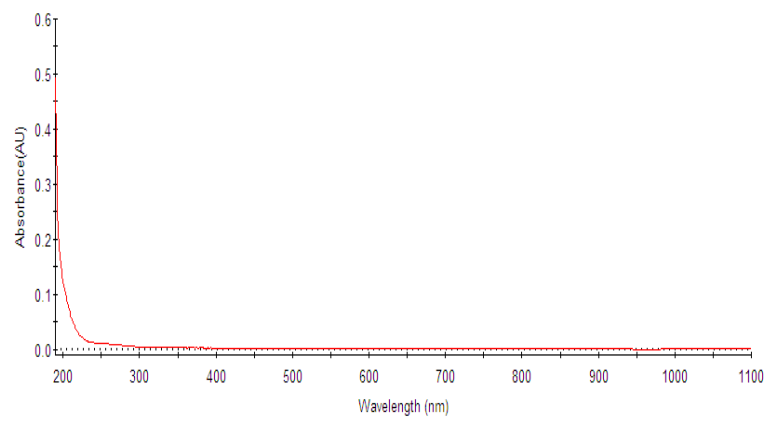

Fig.4(a) Absorption spectrum of LISOL

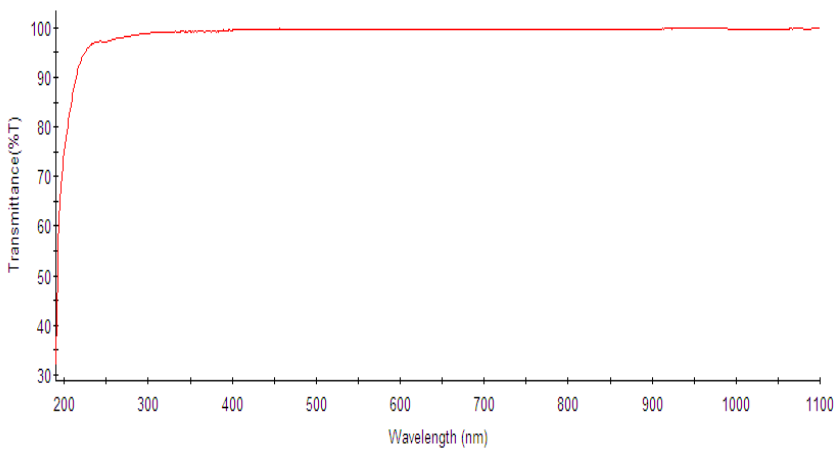

Fig.4(b) Transmission spectrum of LISOL

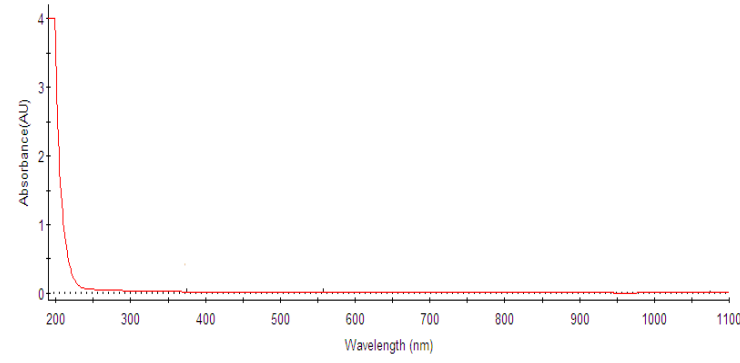

Fig.4(c) Absorption spectrum of LISZA

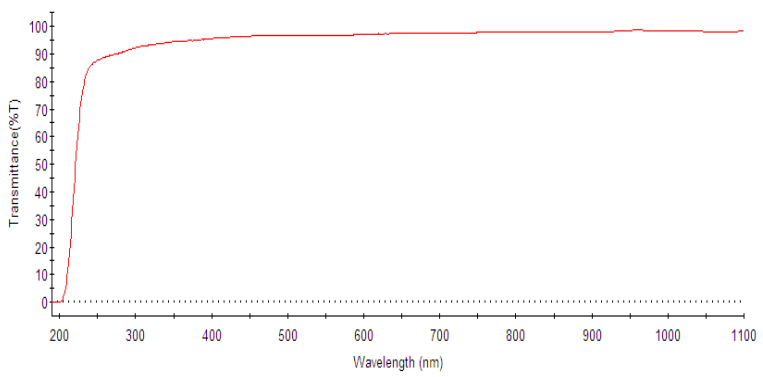

Fig.4(d) Transmission spectrum of LISZA

\section{d. SEM analysis :}

Fig.5(a) shows the structural morphology of pure isoleucine crystal. The image reveals some irregularities in the surface with bulk growth, whereas, zinc acetate mixed isoleucine crystal surface morphology shows the intergranular fracture in its appearance.

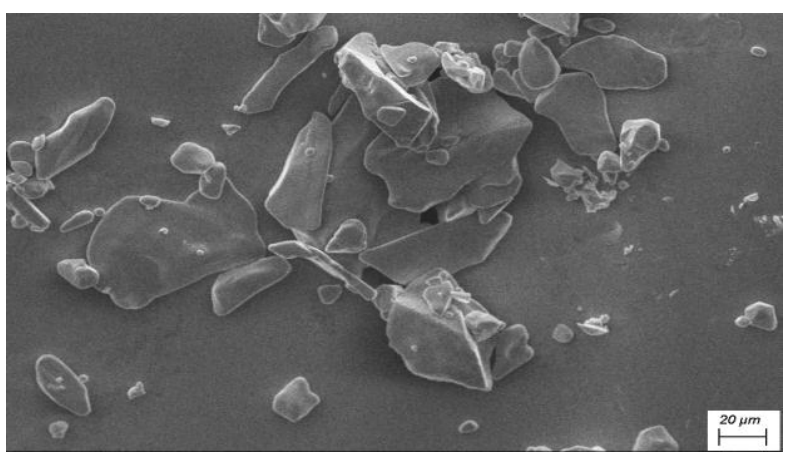

Fig.5(a) SEM image of LISOL

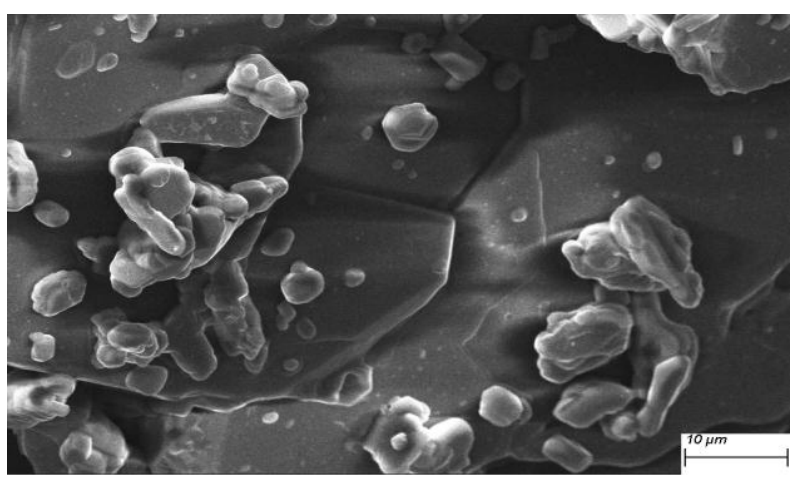

Fig.5(b) SEM image of LISZA 


\section{CONCLUSION}

Single crystals of iso leucine and zinc acetate mixed iso leucine have been grown by slow evaporation technique. The fluorescence spectra of both crystals are observed. FTIR spectrum reveals the functional groups of the grown title compound material are optimistic. The crystal has good optical character in the entire UV-Visible region. SEM analysis discloses the structural morphology of LISOL and LISZA crystals. Further this new crystal material may be considered for opto electronic applications.

\section{ACKNOWLEDGEMENTS}

The authors are thankful to ACIC, St. Joseph's College for the spectral studies.

\section{REFERENCES}

[1]Tanusree K., Amino acids-precursors for synthesizing non linear optical.Mater.Prog.Cryst. Growth Ch.Mat., 2012, 58,74-83.

[2] George Socrates, Infrared and Raman Characteristics group frequencies Tables and Charts, $3^{\text {rd }}$ Edition.

[3] Foil A. Miller and Charles H. Wilkins, Infrared Spectra and characteristic frequencies of inorganics ions,vol.24.no.8Aug.1952[1253-1294].

[4] John Coates, Interpretation of Infrared spectra, A practical approach, Encyclopedia of analytical chemistry, John Wiley and son Ltd., Chichester(2000)[1-23].

[5] Jospeh B. Lambert,et.al, Introduction to organic spectroscopy, MacMillan Pub.NY(1987). 